Manen, J.G. van, Bindels, P.J.E., Dekker, F.W., Bottema, B.J.A.M., Zee, J.S. van der, IJzermans, C.J., Schadé, E.

The influence of COPD on health-related quality of life independent of the influence of comorbidity. Journal of Clinical Epidemiology: 56, 2003, nr. 12, p. 1177-1184

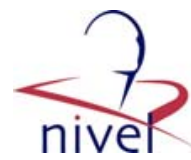

\begin{tabular}{|l|l|}
\hline Postprint Version & 1.0 \\
\hline Journal website & $\underline{\mathrm{http}: / / \text { /inkinghub.elsevier.com }}$ \\
\hline Pubmed link & $\begin{array}{l}\text { http://www.ncbi.nlm.nih.gov/entrez/query.fcgi?cmd=Retrieve\&db=pubmed\&dop } \\
\mathrm{t}=\text { Abstract\&list uids=14680668\&query_hl=9\&itool=pubmed_docsum }\end{array}$ \\
\hline DOI & $\begin{array}{l}\text { 10.1016/S0895-4356(01)00346-8 } \\
\text { This is a NIVEL certified Post Print, more info at http://www.nivel.eu }\end{array}$
\end{tabular}

\title{
The influence of COPD on health-related quality of life independent of the influence of comorbidity
}

\author{
JEANNETTE G. VAN MANEN ${ }^{A, *}$, PATRICK J.E. BINDELS ${ }^{A}$, FRIEDO W. DEKKER ${ }^{\mathrm{B}}$, BERNARDUS J.A.M. \\ BOTTEMA $^{\mathrm{C}}$, JARING S. VAN DER ZEE ${ }^{\mathrm{D}}$, C. JORIS IJZERMANS ${ }^{\mathrm{A}}$, EGBERT SCHADÉ ${ }^{\mathrm{A}}$ \\ ${ }^{a}$ Department of General Practice, Division of Public Health, Academic Medical Center-University of \\ Amsterdam, P.O. Box 22660, 1100 DD, Amsterdam, The Netherlands \\ ${ }^{b}$ Department of Clinical Epidemiology, Leiden University Medical Center, P.O. Box 2300, 2300 RC, \\ Leiden, The Netherlands \\ ${ }^{\mathrm{c}}$ Department of General Practice and Social Medicine, University of Nijmegen, P.O. Box 9101, 6500 \\ $\mathrm{HB}$, Nijmegen, The Netherlands \\ ${ }^{d}$ Department of Pulmonology, Academic Medical Center-University of Amsterdam, P.O. Box 22660, \\ 1100 DD, Amsterdam, The Netherlands \\ * Corresponding author. Tel.: 31-0-71-526-6914; fax: 31-0-71-526-6994. E-mail address: \\ j.g.van_manen@lumc.nl (J.G.van Manen).
}

\begin{abstract}
Background and Objective: The goal of this study was to determine the influence of chronic obstructive pulmonary disease (COPD) on health-related quality of life (HRQL) independent of comorbidity.

Methods: Patients with COPD in general practice, $\geq 40$ years, were selected. To recruit controls, a random sample of persons without COPD and $\geq 40$ years, was taken. HRQL was assessed with the SF-36 and comorbidity was determined by questionnaire.

Results: The influence of COPD on HRQL independent of comorbidity (represented by adjusted regression coefficients) was significant for physical functioning (-27.6), role functioning due to physical problems (-21.6), vitality $(-14.4)$, and general health $(-25.7)$, and was minor and not significant for social functioning (-5.6), mental health (-1.3), role functioning due to emotional problems $(-2.7)$, and bodily pain $(-2.5)$. Comorbidity contributed significantly to the HRQL of all domains (-7.6 to -27.1$)$.

Conclusion: COPD patients can be impaired in all domains of HRQL. However, impairments in physical functioning, vitality, and general health are related to COPD and to some extent to comorbidity, while impairments in social and emotional functioning do not seem to be related to COPD, but only to comorbidity.
\end{abstract}

\section{INTRODUCTION}

Because pulmonary function is chronically and irreversibly impaired in chronic obstructive pulmonary disease (COPD) patients, it is widely recognized that the treatment of COPD patients should not be directed only towards pulmonary function. Additionally, the minimization of the patients' symptoms and the improvement of the ability to function in day-to-day life, or, in other words, the improvement of health-related quality of life (HRQL), are important therapeutic goals in COPD patients [1]. Knowledge about the HRQL impairments in COPD patients is needed, because 
Manen, J.G. van, Bindels, P.J.E., Dekker, F.W., Bottema, B.J.A.M., Zee, J.S. van der, IJzermans, C.J., Schadé, E.

The influence of COPD on health-related quality of life independent of the influence of comorbidity. Journal of Clinical Epidemiology: 56, 2003, nr. 12, p. 1177-1184

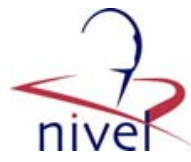

this gives information on the specific problems that patients experience and may, therefore, guide treatment priorities and adequate care.

In studies that compared the HRQL of COPD patients to the HRQL of controls, patients and controls were often comparable with respect to age or gender [2-10]. However, the results were not adjusted for the presence of comorbidity, even though other chronic conditions frequently occur in COPD patients and also occur more often than in controls (general populations) [11].

Although it is apparent from previous studies that COPD patients have worse HRQL than controls, it is unclear whether the observed differences between COPD patients and controls can be attributed to the influence of COPD itself or to the influence of other chronic conditions. This is an important issue because if the impairments in COPD patients do not particularly appear to be the consequence of COPD itself, efforts to improve the HRQL in COPD patients should focus less on problems that are specifically associated with COPD, but should focus relatively more on problems that are associated with comorbidity. The aim of the present study was therefore to determine the influence of COPD on different aspects of HRQL independent of the influence of comorbidity and other prognostic variables.

\section{METHODS}

\subsection{Selection of COPD patients}

A COPD patient was defined as a patient with an FEV1/ VC-ratio before and after inhalation of 400 $\mu \mathrm{g}$ salbutamol below the reference ratio minus $1.64 \times$ standard deviation, an FEV $1<80 \%$ predicted, a reversibility in FEV1\% pred $\leq 12 \%$, and a history of smoking. These patients were selected in 28 general practices from urban and suburban regions in the western part of The Netherlands, and selection was carried out in three consecutive steps [1]. Because spirometry is not always performed to differentiate between COPD and asthma in general practice, misclassification of COPD patients can occur, especially in the elderly, in which there is an important overlap between the two entities. Therefore, all patients who were registered with a diagnosis of asthma or COPD in their general practice and who were at least 40 years old were selected from the patient list in each practice [2]. The general practitioners (GP) were asked to exclude patients who met the following criteria: poor cognitive functioning $(n=47)$, a poor mastering of the Dutch language $(n=46)$, and presence of an end-stage disease $(n=33)$ [3]. Of the eligible subjects $(n=1106), 606$ were willing to participate and filled in the questionnaire on comorbidity completely (response 55\%). Patients who met the abovementioned lung function criteria for COPD were included $(n=148)$. All other patients were considered to have asthma or no obstructive airway disease, and were thus excluded from the analyses. Lung function data and questionnaire data were obtained on the same day between December 1996 and October 1999.

\subsection{Selection of controls}

A random sample of 676 persons was taken from all patients from 13 general practices, who were not labeled by the GP as having asthma or COPD and who were 40 years or older (an initial sample of 700 controls was taken - which we thought could guarantee a control population of at least the size of the patient population - of which 24 controls appeared not to belong to the patient list). The 13 practices were part of and representative for the 28 practices from which patients were selected. As in The Netherlands almost all persons are registered with a GP, the sample can be considered representative for the general population. The sample was stratified: 178 patients were selected from patients who were 40 to 60 years of age, and 498 patients were selected from patients who were 60 years or older. The general practitioners were asked to exclude patients with poor cognitive functioning $(n=26)$, a poor mastering of the Dutch language $(n=7)$ or with an end-stage disease $(n=1)$. Of the 642 eligible patients, 384 patients were willing to participate and filled in the questionnaire on comorbidity completely (response is 60\%). Additionally, all patients with self-reported asthma or COPD but not labeled as such by the GP $(n=20)$ were excluded.

\subsection{Data collection procedures}

HRQL was determined by the SF-36, a generic measure that is broadly used and validated [12]. The SF-36 is composed of 36 questions, organized into eight multi-item scales: physical functioning (PF), role limitations due to physical health problems (RP), social functioning (SF), mental health (MH), 
Manen, J.G. van, Bindels, P.J.E., Dekker, F.W., Bottema, B.J.A.M., Zee, J.S. van der, IJzermans, C.J., Schadé, E.

The influence of COPD on health-related quality of life independent of the influence of comorbidity. Journal of Clinical Epidemiology: 56, 2003, nr. 12, p. 1177-1184

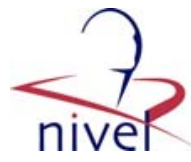

role limitations due to emotional problems (RE), vitality (VT), bodily pain, (BP) and general health $(\mathrm{GH})$. All raw scale scores are linearly converted to a 0 to 100 scale, with higher scores indicating a better HRQL.

To determine the presence of diseases, patients and controls were asked to complete a questionnaire on 23 diseases or symptoms. This questionnaire is developed by the Statistics Netherlands, and is broadly used in demographic studies in The Netherlands [13]. Diseases included in the questionnaire had a prevalence of more than $2 \%$, and were long-lasting by nature. In the questionnaire, patients were asked whether they were suffering from each of the 23 diseases at that moment. Diseases were described in a way it was understandable for patients. For example, the term "high blood pressure" was used instead of "hypertension." The following diseases were listed: locomotive diseases (rheumatoid arthritis, arthrosis, slipped disc, disorder of the back for $>3$ months), hypertension, insomnia, serious heart diseases or myocardial infarction, sinusitis, migraine, depression, dizziness with falling, ulcer stomach/duodenum, cancer, atherosclerosis, thyroid diseases, diabetes, serious intestinal diseases for $>3$ months, serious skin diseases, gall bladder diseases, stroke, chronic cystitis, kidney stones, thrombosis, epilepsy, liver diseases, and renal diseases.

In addition, questions were asked on gender, age, living situation (living alone or living with others), and education (low: primary school, lower vocational training, school for lower general secondary education; high: pre-university education, high vocational training, university).

Lung function impairment was assessed by spirometry before and after inhalation of $400 \mu \mathrm{g}$ salbutamol using a pneumotach (MasterScope, Jaeger, Germany) according to the European Respiratory Society guidelines for measurement [14], and carried out by trained personnel.

The study was approved by the medical ethics committee of the Academic Medical CenterUniversity of Amsterdam.

\subsection{Analysis}

$t$-Tests and Mann-Whitney tests were carried out to test whether the mean scores of the SF-36 differed between patients and controls. Nonparametric tests were also used because the domains of the SF-36 were formally not normally distributed. However, no differences were found between the parametric and nonparametric tests (i.e., no differences in whether $P$-value was smaller than .05). Furthermore, linear regression analyses were carried out to adjust for potential confounders. In these analyses, an SF-36 domain was the dependent variable, and the independent variables were the research group (COPD or control), comorbidity (present or not), and the interaction term between these two variables. Covariates were age, gender, education, and living situation. The multivariate analyses were performed with and without each of the potential confounders included in the models. When including or excluding the confounders in any of the models, the beta parameters for COPD, comorbidity, or the interaction term between these two parameters never differed to such an extent that different conclusions had to be drawn. Therefore, the results are shown only for the models in which all potential confounders were included. $P$-values $<.05$ were considered statistically significant. All analyses were carried out using SPSS 8.0 for Windows.

\section{RESULTS}

\subsection{General characteristics}

Of all COPD patients, $72 \%$ was suffering from comorbidity, and $63 \%$ of all controls had one or morechronic conditions (Table 1).COPD patients and controls with comorbidity were older $(\geq 60$ years) than COPD patients and controls without comorbidity ( 81 and $76 \%$ vs. 66 and 59\%). They also were less often men ( 68 and $42 \%$ vs. 73 and $43 \%$ ), had more often a low education ( 86 and $83 \%$ vs. 82 and $70 \%$ ), and lived more often alone (28 and $27 \%$ vs. 20 and $15 \%$ ). In COPD patients $73 \%$ had one or two other chronic diseases and $27 \%$ had three or more diseases. In controls, $83 \%$ had one or two chronic diseases and $17 \%$ had three or more chronic diseases.

\section{[ TABLE 1 ]}


Manen, J.G. van, Bindels, P.J.E., Dekker, F.W., Bottema, B.J.A.M., Zee, J.S. van der, IJzermans, C.J., Schadé, E.

The influence of COPD on health-related quality of life independent of the influence of comorbidity. Journal of Clinical Epidemiology: 56, 2003, nr. 12, p. 1177-1184

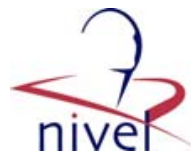

\subsection{Influence of COPD on HRQL independent of comorbidity}

To investigate the influence of COPD on HRQL independent of comorbidity, the mean SF-36 scores of COPD patients with and without comorbidity were compared to the mean SF-36 scores of controls with and without comorbidity (Table 2). It appeared that COPD patients without comorbidity had statistically significantly lower scores than controls without comorbidity for physical functioning $(60.0$ vs. 89.0), role functioning due to physical problems (68.2 vs. 91.9), social functioning (83.2 vs. 90.6), vitality (61.1 vs. 73.7$)$, and general health (49.1 vs. 76.1$)$. COPD patients with comorbidity had statistically significantly lower scores than the scores of controls with comorbidity for physical functioning (50.0 vs. 67.7), and general health (45.8 vs. 60.9).

\section{[ TABLE 2 ]}

Furthermore, the relative contribution of COPD and comorbidity on HRQL was investigated by performing a linear regression analysis in which the results also were adjusted for demographic variables. Table 3 shows the regression coefficients of the linear regression model. With these regression coefficients the differences in mean scores for each domain between COPD patients and controls can be calculated. This has been visualized in Figs. 1-3, in which different subgroups are compared (1, COPD without comorbidity vs. controls without comorbidity, 2, COPD patients with comorbidity vs. controls with comorbidity, and 3, COPD patients with comorbidity vs. controls without comorbidity). For example, the mean score for physical functioning of COPD patients with comorbidity is 34 points $(-22.0-12.0)$ lower than the mean score of controls without comorbidity, which can be seen in Fig. 3.

\section{[ TABLE 3 ]}

\section{[ FIGURES 1-3 ]}

In general, the multivariate analyses show the same results as the univariate analyses. The influence of COPD on HRQL independent of comorbidity was statistically significant for physical functioning (22.0 ), and role functioning due to physical problems (-15.3). Because the interaction between COPD and comorbidity was significant for vitality and general health, the influence of COPD differed between COPD patients with and without comorbidity. COPD affects vitality with an average of 5.7 points $(-14.4+8.7)$ in COPD patients with comorbidity, while it affects vitality with an average of 14.4 points in COPD patients without comorbidity. COPD affects general health, with an average of 15.7 and 25.7 in COPD patients with and without comorbidity, respectively. The influence of COPD was minor and not significant for social functioning (-6.8), mental health (-2.5), role functioning due to emotional problems $(-6.3)$, and bodily pain $(-2.5)$. The influence of COPD independent of the influence of comorbidity can also be seen in Figures 1 and 2. Comorbidity contributed significantly to the HRQL of all domains (Table 3). From this table, it can also be seen that the relative contribution of COPD and comorbidity differed between the domains. The influence of COPD was larger than the influence of comorbidity for physical functioning (-22.0 vs. -12.0$)$ and general health $(-25.7$ or -15.7 vs. -13.0). The influence of comorbidity, however, was much more pronounced than the influence of COPD for role functioning due to physical problems (-24.7 vs. -15.3$)$, mental health (-8.0 vs. -2.5$)$, role functioning due to emotional problems (-16.2 vs. -6.3$)$, and bodily pain (-16.3 vs. -2.5$)$. Because comorbidity significantly affects all domains of HRQL, COPD patients with comorbidity have an impaired HRQL on all domains when compared to controls without comorbidity, which can be seen in Fig. 3.

Finally, Table 3 shows the influence of age, gender, education, and living situation on HRQL. Age negatively affects physical functioning (-0.8 for each year), role functioning due to physical problems $(-0.6)$, and general health $(-0.2)$, and positively affects mental health ( 0.2 for each year). Males have, in general, a better HRQL than females, while education is only significantly related to mental health (4.0 points lower for low education), and living situation to physical functioning (6.4 lower for living alone) and mental health (-7.9). 
Manen, J.G. van, Bindels, P.J.E., Dekker, F.W., Bottema, B.J.A.M., Zee, J.S. van der,

IJzermans, C.J., Schadé, E.

The influence of COPD on health-related quality of life independent of the influence of comorbidity.

Journal of Clinical Epidemiology: 56, 2003, nr. 12, p. 1177-1184

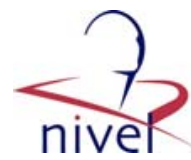

\section{DISCUSSION}

The question of the present study was whether the impairments that are seen in COPD patients can indeed be attributed to COPD — which has been assumed so far - or to comorbid diseases that are very common in these patients. We found that the impairments in physical functioning, role functioning due to physical problems, vitalitym and general health are to a large extent related to COPD, but also to comorbidity. However, impairments in the HRQL domains social functioning, mental health, and role functioning due to emotional problems do not seem to be related to COPD. These latter HRQL domains seem primarily related to the presence of comorbidity rather than to COPD itself.

There were some limitations of this study that need to be mentioned. First, there was some dropout in this study. Both in COPD patients and controls, the most important reason for dropout was feeling too ill or too old to participate ( $26 \%$, respectively $24 \%$ ). Other reasons were: unable to find time, personal circumstances, psychiatric problems, unable to fill in questionnaire, and other. Consequently, the most ill patients and controls probably have not been compared with each other. Whether the impairments seen in the COPD patients that participated in this study also apply to patients with more severe COPD therefore still needs to be investigated. However, because the COPD patients included in our study had a wide range of airway obstruction, we expect the data to be valid for the majority of COPD patients seen in general practice.

A second limitation of the study may be that the results of our study were based on a subjective measure of comorbidity, namely the self-report of patients. Several studies have indicated that patients' self-reports are fairly accurate [15-17]. However, for some diseases agreement between questionnaire data and medical record data is rather poor, for example, in the case of locomotive diseases $[15,16]$.These diseases may reflect a symptom rather than a physician-diagnosed disease. The data on these diseases should, therefore, be interpreted as such. Nevertheless, these data are expected to be valid for assessing the symptom rather than the diagnosis, because patients are considered to be the best experts in reporting perceived disease symptoms.

Another limitation of the study may be that comorbidities were differently distributed among patients and controls. In an earlier study in which we focussed on the influence of specific comorbidities on HRQL next to several other clinical characteristics, we showed that the number of comorbid diseases, rather than the type of disease, seems to cause impairments in HRQL in COPD patients [20]. Because COPD patients with comorbidity had more comorbidities than controls with comorbidity, it might be concluded that the differences in HRQL between these two groups may not only be attributed to the effect of COPD, but also to differences in the distribution of comorbidity between the groups. Consequently, it might be concluded that the effect of COPD on HRQL could have been overestimated. However, when comparing COPD patients without comorbidity to controls without comorbidity, we found essentially the same - and even bigger - differences between the groups, indicating that it is unlikely that the effect of COPD on HRQL is overestimated due to differences in the distribution of comorbidity between COPD patients and controls.

Another limitation of the study may be that empirical evidence for meaningful cut-off points to define clinical relevant differences does not exist for the SF-36. For this reason it is difficult to interpret the differences that we found between groups. Furthermore, because standard deviations differ between domains, it should be noted that (differences in) SF-36 scores cannot be compared across domains. However, in the present study we focus on the relative contribution of COPD and comorbidity (e.g., the contribution of COPD and comorbidity is similar for vitality, while comorbidity is related to bodily pain and COPD is not). This relative contribution of these two factors can be compared between domains. Furthermore, in the absence of criteria to define clinically relevant differences and difficulties in comparing scores across domains, we used a $P$-value less than .05 as a criterion to establish whether there is an impact of either COPD or comorbidity on any of the SF-36 domains.

We used the SF-36 - a generic instrument for HRQL - in our study instead of a disease-specific instrument, because comorbidity was of particular interest in this study. As a generic instrument, in contrast to a disease-specific instrument, is designed to measure the consequences of a variety of diseases, such an instrument would be able to demonstrate whether the influence of COPD on HRQL is different from the influence of comorbidity on HRQL. 
Manen, J.G. van, Bindels, P.J.E., Dekker, F.W., Bottema, B.J.A.M., Zee, J.S. van der, IJzermans, C.J., Schadé, E.

The influence of COPD on health-related quality of life independent of the influence of comorbidity. Journal of Clinical Epidemiology: 56, 2003, nr. 12, p. 1177-1184

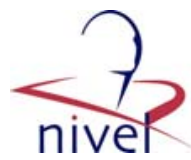

Several other studies on HRQL in COPD patients and controls also used the SF-36 to assess HRQL $[5,7,10]$. Although the HRQL-scores depended to some extent on the characteristics of the population that was included, these studies showed that COPD patients can be impaired on all domains of the SF36. In our study we were able to demonstrate that COPD particularly seems to influence physical functioning, role functioning due to physical problems, vitality, and general health and has limited or no influence on other domains (social, emotional, pain). The influence of COPD on physical and general domains and vitality can be explained by the disabling effects of breathlessness, which is one of the most prominent symptoms in COPD patients. This idea is supported by previous studies in which associations between SF-36 domains and dyspnea particularly exist for these physical and general domains $[5,10,18,19]$.

In the present study, in which we tried to establish the impact of COPD per se on HRQLindependent of that influence of comorbidity - we found that the observed impairments in COPD patients can be attributed to COPD only for a number of specific dimensions. In contrast, comorbidity was related to impairments in all domains. An explanation for this may be that COPD and other chronic diseases differently affect HRQL. Another explanation may be that coping mechanisms can prevent social or emotional problems in COPD patients, but these might fail when COPD patients are confronted with other diseases as well.

COPD appeared to have smaller effects in COPD patients with comorbidity than in COPD patients without comorbidity for vitality and general health. An explanation for this may be that patients with any disease (COPD or any comorbidity) are affected to a certain extent on these more global domains; whether it is due to one disease (COPD alone) or more diseases (COPD + comorbidity) does not matter that much. On top of comorbidity, COPD has limited effect; the maximal impairments for these domains may have been reached already.

The impairments in physical functioning and general health that seem to be affected by COPD in this study, have also been shown to improve after pulmonary rehabilitation [21-23]. This is another indication that impairments in these domains are specifically related to COPD. Furthermore, the observation that emotional and social domains of quality of life seem to be impaired due to comorbidity and not due to COPD would imply that pulmonary rehabilitation cannot be expected to improve these domains. Also, because comorbidity may impair physical domains, vitality, and general health in addition to COPD, pulmonary rehabilitation may have limited impact on these domains as well in COPD patients with comorbidity.

Only one study addressed the role of comorbidity in COPD patients [9]. In that study only total HRQL scores were investigated, and no distinction was made between the different domains of HRQL. Furthermore, the results in COPD patients were compared with results in the general population that, by definition, includes healthy controls as well as controls with chronic conditions. Although the study clearly showed that comorbidity had a negative influence on overall HRQL, no conclusions could be drawn on the independent influence of COPD on specific domains of HRQL.

In conclusion, COPD patients can be impaired in all domains of HRQL, i.e. their physical, as well as social and emotional functioning can be affected. However, in this study that was not confounded by comorbidity, we found evidence that COPD itself particularly affects physical functioning, vitality, and general health. Nevertheless, these domains can be additionally impaired due to comorbidity as well. Impairments in social and emotional functioning do not seem to be problems that are specifically related to COPD. Instead, they rather seem related to other chronic diseases that are frequently present in COPD. Therefore, research needs to be done on the influence of specific diseases on HRQL in COPD patients.

\section{ACKNOWLEDGMENTS}

This study was supported by Boehringer Ingelheim NL by supplying all materials and personnel for the lung function testing. 
Manen, J.G. van, Bindels, P.J.E., Dekker, F.W., Bottema, B.J.A.M., Zee, J.S. van der,

IJzermans, C.J., Schadé, E.

The influence of COPD on health-related quality of life independent of the influence of comorbidity.

Journal of Clinical Epidemiology: 56, 2003, nr. 12, p. 1177-1184

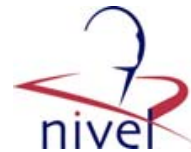

\section{TABLES AND FIGURES}

Table 1

General characteristics of COPD patients and controls with and without comorbidity

\begin{tabular}{|c|c|c|c|c|c|c|c|c|}
\hline & COPD 1 & $n=148$ & & & Controls, & & & \\
\hline & Without & bidity & With con & & Without & bidity & With con & dity \\
\hline & $n=41$ & $(27.7 \%)$ & $n=107$ & $(72.3 \%)$ & $n=135$ & $(37.1 \%)$ & $n=229$ & $(62.9 \%)$ \\
\hline$\geqslant 60$ years & 27 & $(65.9)$ & 87 & $(81.3)$ & 79 & $(58.5)$ & 174 & $(76.0)$ \\
\hline Male & 30 & $(73.2)$ & 73 & $(68.2)$ & 58 & $(43.0)$ & 96 & $(41.9)$ \\
\hline Low education & 31 & (81.6) & 92 & $(86.0)$ & 89 & $(70.1)$ & 178 & $(82.8)$ \\
\hline Living alone & 8 & (19.5) & 30 & $(28.0)$ & 20 & $(14.9)$ & 62 & $(27.4)$ \\
\hline FEV $1<50 \%$ predicted & 16 & $(39.0)$ & 39 & $(36.4)$ & - & & - & \\
\hline FEV1 $50-70 \%$ predicted & 12 & $(29.3)$ & 45 & $(42.1)$ & - & & - & \\
\hline FEV1 $70-80 \%$ predicted & 13 & $(31.7)$ & 23 & $(21.5)$ & - & & - & \\
\hline $1-2$ chronic diseases $^{a}$ & - & & 78 & (72.9) & - & & 189 & $(82.5)$ \\
\hline 3-4 chronic diseases & - & & 23 & $(21.5)$ & - & & 32 & $(14.0)$ \\
\hline$\geqslant 5$ chronic diseases & - & & 6 & $(5.6)$ & - & & 8 & $(3.5)$ \\
\hline Locomotive diseases & & & 54 & $(50.5)$ & & & 97 & $(42.4)$ \\
\hline High blood pressure & & & 28 & $(26.2)$ & & & 68 & $(29.7)$ \\
\hline Heart disease & & & 23 & $(21.5)$ & & & 36 & $(15.7)$ \\
\hline Insomnia & & & 18 & $(16.8)$ & & & 38 & $(16.6)$ \\
\hline Sinusitis & & & 12 & (11.2) & & & 8 & $(3.5)$ \\
\hline Ulcer stomach/duodenum & & & 12 & (11.2) & & & 4 & $(1.7)$ \\
\hline Cancer & & & 12 & (11.2) & & & 8 & $(3.5)$ \\
\hline Dizziness & & & 10 & $(9.3)$ & & & 17 & (7.4) \\
\hline Stroke & & & 8 & $(7.5)$ & & & 9 & (3.9) \\
\hline Migraine & & & 5 & $(4.7)$ & & & 16 & (7.0) \\
\hline Intestinal diseases & & & 5 & $(4.7)$ & & & 10 & $(4.4)$ \\
\hline Kidney stones & & & 5 & $(4.7)$ & & & 9 & $(3.9)$ \\
\hline Depression & & & 4 & (3.7) & & & 11 & $(4.8)$ \\
\hline Atherosclerosis & & & 4 & (3.7) & & & 4 & (1.7) \\
\hline Diabetes & & & 4 & $(3.7)$ & & & 27 & $(11.8)$ \\
\hline Skin diseases & & & 4 & (3.7) & & & 8 & $(3.5)$ \\
\hline Thyroid diseases & & & 2 & (1.9) & & & 16 & (7.0) \\
\hline Gall bladder diseases & & & 2 & (1.9) & & & 6 & (2.6) \\
\hline Chronic cystitis & & & 2 & (1.9) & & & 6 & (2.6) \\
\hline Thrombosis & & & 1 & $(0.9)$ & & & 10 & (4.4) \\
\hline Epilepsy & & & 1 & (0.9) & & & 3 & (1.3) \\
\hline Liver diseases & & & 0 & - & & & 2 & $(0.9)$ \\
\hline Renal diseases & & & 0 & - & & & 1 & $(0.4)$ \\
\hline
\end{tabular}

${ }^{a}$ In COPD patients, chronic diseases do not include COPD.

Table 2

Health-related quality of life in COPD patients and controls with and without comorbidity. Mean scores (SD)

\begin{tabular}{|c|c|c|c|c|}
\hline Domains SF-36 & $\begin{array}{l}\text { COPD patients } \\
\text { without comorbidity } \\
n=41\end{array}$ & $\begin{array}{l}\text { Controls without } \\
\text { comorbidity } \\
n=135\end{array}$ & $\begin{array}{l}\text { COPD patients } \\
\text { with comorbidity } \\
n=107\end{array}$ & $\begin{array}{l}\text { Controls with } \\
\text { comorbidity } \\
n=229\end{array}$ \\
\hline Physical functioning & $60.0(20.4)^{*}$ & $89.0(16.5)$ & $50.0(26.8)^{*, * * *}$ & $67.7(28.5)$ \\
\hline Role functioning-physical & $68.2(32.7)^{*}$ & $91.9(20.2)$ & $48.1(43.6)^{*}$ & $57.9(44.5)$ \\
\hline Social functioning & $83.2(21.4)^{*}$ & $90.6(14.6)$ & $72.0(28.7)^{*}$ & $77.9(24.0)$ \\
\hline Mental health & $79.3(13.0)$ & $80.7(14.5)$ & $71.2(20.8)^{*}$ & $72.6(18.4)$ \\
\hline Role functioning-emotional & $87.8(26.6)$ & $90.2(26.8)$ & $67.9(42.8)^{*}$ & $71.5(41.2)$ \\
\hline Vitality & $61.1(14.4)^{*}$ & $73.7(15.9)$ & $55.9(23.4)^{*}$ & $59.4(21.0)$ \\
\hline Bodily pain & $88.8(18.5)$ & $90.4(15.0)$ & $83.6(23.2)^{* * * * *}$ & $72.8(24.9)$ \\
\hline General health & $49.1(15.9)^{*}$ & $76.1(15.7)$ & $45.8(20.4)^{* * * * *}$ & $60.9(17.8)$ \\
\hline
\end{tabular}

$* P<.05$ ( $t$-test/Mann-Whitney, reference group is controls without comorbidity)

** $P<.05$ ( $t$-test/Mann-Whitney, reference group is controls with comorbidity) 
Manen, J.G. van, Bindels, P.J.E., Dekker, F.W., Bottema, B.J.A.M., Zee, J.S. van der,

IJzermans, C.J., Schadé, E.

The influence of COPD on health-related quality of life independent of the influence of comorbidity.

Journal of Clinical Epidemiology: 56, 2003, nr. 12, p. 1177-1184

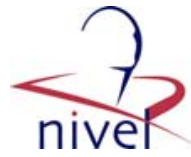

Table 3

Influence of COPD and comorbidity (and interaction between the two) on health-related quality of life, adjusted for age, gender, education, living situation

\begin{tabular}{|c|c|c|c|c|}
\hline & Physical functioning & Role functioning physical & Social functioning & Mental health \\
\hline COPD vs. control & $-22.0(2.3)^{*}$ & $-15.3(3.9) *$ & $-6.8(2.3)$ & $-2.5(1.8)$ \\
\hline comorbidity (yes vs. no) & $-12.0(2.2)^{*}$ & $-24.7(3.8) *$ & $-10.8(2.3)^{*}$ & $-8.0(1.7)^{*}$ \\
\hline interaction term ${ }^{\mathrm{a}}$ & $\mathrm{NS}^{\mathrm{a}}$ & $\mathrm{NS}^{\mathrm{a}}$ & $\mathrm{NS}^{\mathrm{a}}$ & $\mathrm{NS}^{\mathrm{a}}$ \\
\hline Age & $-0.8(0.1)^{*}$ & $-0.6(0.2) *$ & $-0.9(0.1)$ & $0.2(0.1)^{*}$ \\
\hline Gender (male vs. female) & $7.3(2.2)^{*}$ & $6.5(3.6)$ & $2.9(2.2)$ & $4.9(1.6)^{*}$ \\
\hline Education (low vs. high) & $-3.6(2.6)$ & $-2.0(4.4)$ & $0.2(2.7)$ & $-4.0(2.0)^{*}$ \\
\hline Living alone vs. not alone & $-6.4(2.6)^{*}$ & $-7.3(4.4)$ & $-5.0(2.6)$ & $-7.9(2.0)^{*}$ \\
\hline \multirow[t]{2}{*}{$R^{2}$} & $39 \%$ & $20 \%$ & $9 \%$ & $12 \%$ \\
\hline & Role functioning emotional & Vitality & Bodily pain & General health \\
\hline COPD vs. control & $-6.3(3.8)$ & $-14.4(3.7) *$ & $-2.5(4.0)$ & $-25.7(3.3)^{*}$ \\
\hline comorbidity (yes vs. no) & $-16.2(3.7)^{*}$ & $-14.0(2.3)^{*}$ & $-16.3(2.5) *$ & $-13.0(2.1)^{*}$ \\
\hline interaction term ${ }^{\mathrm{a}}$ & $\mathrm{NS}^{\mathrm{a}}$ & $8.7(4.3)^{*}$ & $11.6(4.7)^{*}$ & $10.0(3.9) *$ \\
\hline Age & $-0.2(0.2)$ & $0.2(0.1)$ & $-0.8(0.1)$ & $-0.2(0.1)^{*}$ \\
\hline Gender (male vs. female) & $7.9(3.6)^{*}$ & $5.8(1.9)^{*}$ & $6.5(2.1)^{*}$ & $1.4(1.7)$ \\
\hline Education (low vs. high) & $0.6(4.3)$ & $0.5(2.3)$ & $-1.8(2.5)$ & $-1.6(2.1)$ \\
\hline Living alone vs. not alone & $-7.5(4.3)$ & $-3.5(2.3)$ & $-3.3(2.5)$ & $-2.7(2.1)$ \\
\hline$R^{2}$ & $8 \%$ & $13 \%$ & $14 \%$ & $29 \%$ \\
\hline
\end{tabular}

Linear regression analysis: regression coefficients (SE) and $R^{2}$ are shown

$* p<.05$

${ }^{a}$ Interaction between COPD vs. control and comorbidity (the coefficient for this interaction term is valid for COPD patients with comorbidity, and not for controls or COPD patients without comorbidity), if the interaction term was not significant (NS), it was excluded from the model.

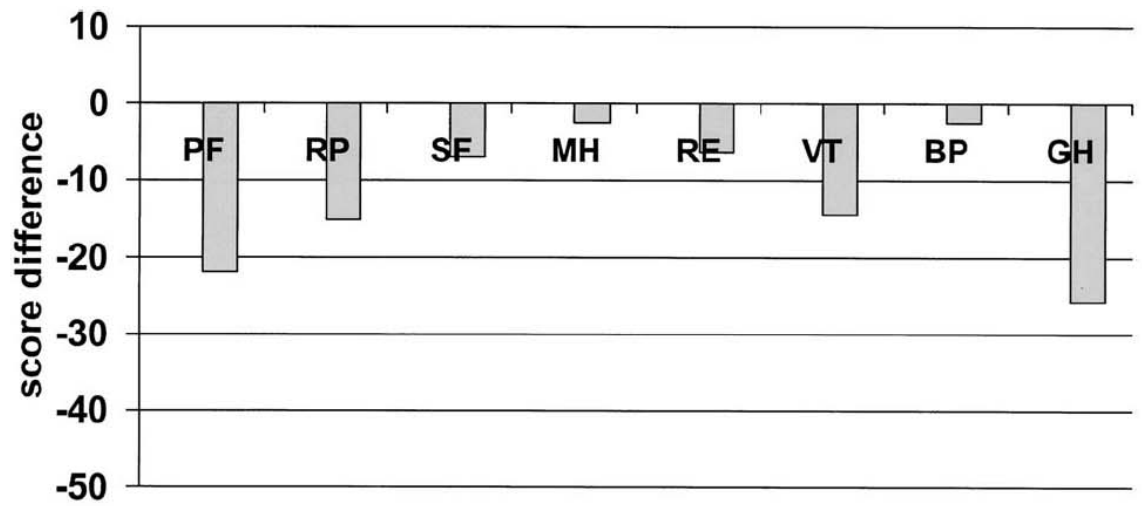

domains SF-36

Fig. 1. Score differences in SF-36: COPD patients without comorbidity vs. controls without comorbidity. Linear regression analyses, adjustment for age, gender, education, and living situation. Abbreviations: $\mathrm{PF}=$ physical functioning; $\mathrm{RP}=$ role-physical; $\mathrm{SF}=$ social functioning; $\mathrm{MH}=$ mental health; $\mathrm{RE}=$ role-emotional; $\mathrm{VT}=$ vitality; $\mathrm{BP}=$ bodily pain; $\mathrm{GH}=$ general health.

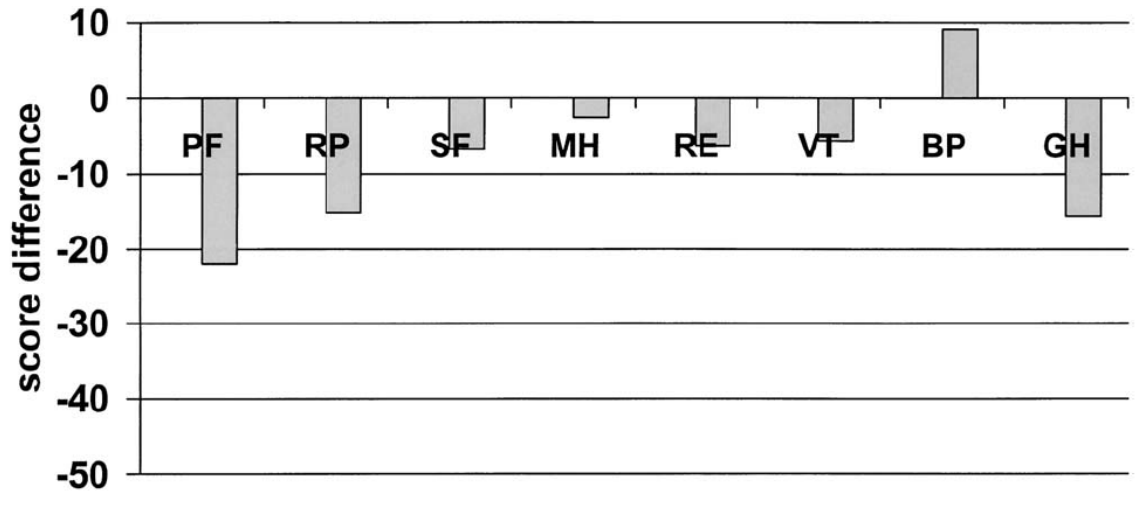

domains SF-36

Fig. 2. Score differences in SF-36: COPD patients with comorbidity vs. controls with comorbidity. Linear regression analyses, adjustment for age, gender, education, and living situation. Abbreviations: $\mathrm{PF}=$ physical functioning; $\mathrm{RP}=$ role-physical; $\mathrm{SF}=$ social functioning; $\mathrm{MH}=\mathrm{mental}$ health; $\mathrm{RE}=$ roleemotional; $\mathrm{VT}=$ vitality; $\mathrm{BP}=$ bodily pain; $\mathrm{GH}=$ general health 
Manen, J.G. van, Bindels, P.J.E., Dekker, F.W., Bottema, B.J.A.M., Zee, J.S. van der, IJzermans, C.J., Schadé, E.

The influence of COPD on health-related quality of life independent of the influence of comorbidity. Journal of Clinical Epidemiology: 56, 2003, nr. 12, p. 1177-1184

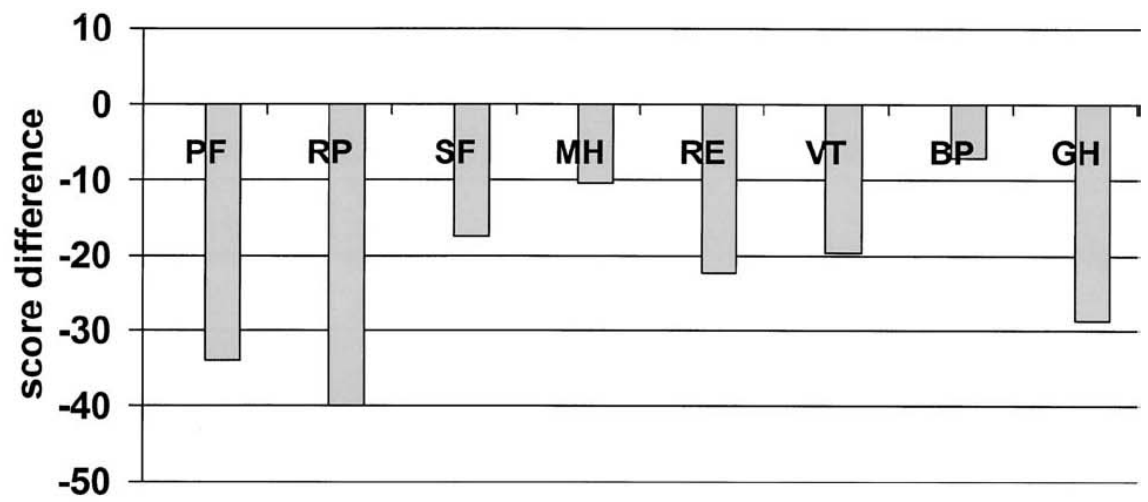

domains SF-36

Fig. 3. Score differences in SF-36: COPD patients with comorbidity vs. controls without comorbidity. Linear regression analyses, adjustment for age, gender, education, and living situation. Abbreviations: $\mathrm{PF}=$ physical functioning; $\mathrm{RP}=$ role-physical; $\mathrm{SF}=$ social functioning; $\mathrm{MH}=\mathrm{mental}$ health; $\mathrm{RE}=$ role-emotional; $\mathrm{VT}=$ vitality; $\mathrm{BP}=$ bodily pain; $\mathrm{GH}=$ general health.

\section{REFERENCES}

1. Curtis JR, Deyo RA, Hudson LD. Pulmonary rehabilitation in chronic respiratory insufficiency. 7.Health-related quality of life among patients with chronic obstructive pulmonary disease. Thorax 1994;49:162-70.

2. McSweeny AJ, Grant I, Heaton RK, Adams KM, Timms RM. Life quality of patients with chronic obstructive pulmonary disease. Arch Intern Med 1982;142:473-8.

3. Prigatano GP, Wright EC, Levin D. Quality of life and its predictors in patients with mild hypoxemia and chronic obstructive pulmonary disease. Arch Intern Med 1984;144:1613-9.

4. Schrier AC, Dekker FW, Kaptein AA, Dijkman JH. Quality of life in elderly patients with chronic non-specific lung disease in family practice. Chest 1990;98:894-9.

5. Viramontes JL, O'Brien B. Relationship between symptoms and health-related quality of life in chronic lung disease. J Gen Intern Med 1994;9:46-8.

6. Engström C, Persson L, Larsson S, Rydén A, Sullivan M. Functional status and well being in chronic obstructive pulmonary disease with regard to clinical parameters and smoking: a descriptive and comparative study. Thorax 1996;51:825-30.

7. Crockett AJ, Cranston JM, Moss JR, Alpers JH. The MOS SF-36 health survey questionnaire in severe chronic airflow limitation: comparison with the Nottingham Health Profile. Qual Life Res 1996;5: 330-8.

8. Renwick DS, Connolly MJ. Impact of obstructive airways disease on quality of life in older adults. Thorax 1996;51:520-5.

9. Ferrer M, Alonso J, Morera J, Marrades RM, Khalaf A, Aguar MC, Plaza V, Prieto L, Antó JM. Chronic obstructive pulmonary disease stage and health-related quality of life. The Quality of Life of Chronic Obstructive Pulmonary Disease Study Group. Ann Intern Med 1997;127:10729.

10. Alonso J, Prieto L, Ferrer M, Vilagut G, Broquetas JM, Roca J, Serra Batlle J, Antó JM. Testing the measurement properties of the Spanish version of the SF-36 Health Survey among male patients with chronic obstructive pulmonary disease. Quality of Life in COPD Study Group. J Clin Epidemiol 1998;51:1087-94.

11. van Manen JG, Bindels PJE, IJzermans CJ, van der Zee JS, Bottema BJAM, Schadé E. Prevalence of comorbidity in patiens with a chronic airway obstruction and controls over the age of 40. J Clin Epidemiol 2001;54:287-93.

12. Aaronson NK, Muller M, Cohen PD, Essink-Bot ML, Fekkes M, Sanderman R, Sprangers MA, te Velde A, Virrips E. Translation, validation, and norming of the Dutch language version of the SF-36 Health Survey in community and chronic disease populations. J Clin Epidemiol 1998;51:1055-68.

13. Statistics Netherlands. Netherlands Health Interview Survey 1981- 1991. The Hague: SDU Publishers/CBS-Publications; 1992.

14. Quanjer PhH, Tammeling GJ, Cotes JE, Pedersen OF, Peslin R, Yernault J-C. Lung volumes and forced ventilatory flows. Report working party standardization of lung function tests European Community for Steel and Coal. Official statement of the European Respiratory Society. Eur Respir J 1993;6:5-40. 
Manen, J.G. van, Bindels, P.J.E., Dekker, F.W., Bottema, B.J.A.M., Zee, J.S. van der, IJzermans, C.J., Schadé, E.

The influence of COPD on health-related quality of life independent of the influence of comorbidity. Journal of Clinical Epidemiology: 56, 2003, nr. 12, p. 1177-1184

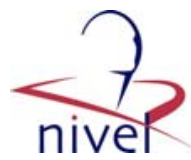

15. Haapanen N, Miilunpalo S, Pasanen M, Oja P, Vuori I. Agreement between questionnaire data and medical records of chronic diseases in middle-aged and elderly Finnish men and women. Am J Epidemiol 1997;145:762-9.

16. Kriegsman DM, Penninx BW, van Eijk JT, Boeke AJ, Deeg DJ. Selfreports and general practitioner information on the presence of chronic diseases in community dwelling elderly. A study on the accuracy of patients' self-reports and on determinants of inaccuracy. J Clin Epidemiol 1996;49:1407-17.

17. Katz JN, Chang LC, Sangha O, Fossel AH, Bates DW. Can comorbidity be measured by questionnaire rather than medical record review? Med Care 1996;34:73-84.

18. Harper R, Brazier JE, Waterhouse JC, Walters SJ, Jones NM, Howard P. Comparison of outcome measures for patients with chronic obstructive pulmonary disease (COPD) in an outpatient setting. Thorax 1997; 52:879-87.

19. Mahler DA, Mackowiak JI. Evaluation of the short-form 36-item questionnaire to measure health-related quality of life in patients with COPD. Chest 1995;107:1585-9.

20. van Manen JG, Bindels PJ, Dekker EW, IJzermans CJ, Bottema BJ, van der Zee JS, et al. Added value of co-morbidity in predicting health-related quality of life in COPD patients. Respir Med 2001;95:496-504.

21. Moy ML, Ingenito EP, Mentzer SJ, Evans RB, Reilly JJJ. Health-related quality of life improves following pulmonary rehabilitation and lung volume reduction surgery. Chest 1999;115:383-9.

22. Camp PG, Appleton J, Reid WD. Quality of life after pulmonary rehabilitation: assessing change using quantitative and qualitative methods. Phys Ther 2000;80:986-95.

23. Griffiths TL, Burr ML, Campbell IA, Lewis-Jenkins V, Mullins J, Shiels K, Turner-Lawlor RJ, Payne N, Newcombe RG, Lonescu AA, Thomas J, Tunbridge J. Results at 1 year of outpatient multidisciplinary pulmonary rehabilitation: a randomised controlled trial. Lancet 2000;355:3628. 